\title{
A FINANCEIRIZAÇÃO DAS CIDADES E A EMENDA CONSTITUCIONAL 95
}

\section{The financialization of cities and the Constitutional amendment 95}

\author{
Ana Beatriz Oliveira Reis (UFOPA) \\ Luccas Assis Attílio (UFOP) \\ Informações do artigo \\ Recebido em 28/03/2018 \\ Aceito em 08/05/2018
}

doi>: https://doi.org/10.25247/2447-861X.2019.n246.p169-195

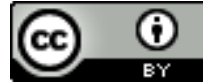

Esta obra está licenciada com uma Licença Creative Commons Atribuição 4.0 Internacional.

Como ser citado (modelo ABNT)

REIS, Ana Beatriz Oliveira; ATTÍLIO, Luccas Assis. A financeirização das cidades e a Emenda constitucional 95. Cadernos do CEAS: Revista Crítica de Humanidades, Salvador, n. 246, jan./abr., p. 169-195, 2019. DOI: https://doi.org/10.25247/2447-

861X.2019.n246.p169-195

\begin{abstract}
Resumo
Nesse artigo analisamos o impacto da EC 95 sobre a financeirização urbana da economia brasileira. Especial atenção é concedida à tendência de mercantilização das cidades, ao mesmo tempo em que direitos sociais e participação popular na formulação de políticas públicas podem ser reduzidos em decorrência do aprofundamento do neoliberalismo no Brasil. Para essa análise, adotamos a metodologia interdisciplinar recorrendo a estudos de diferentes campos. As técnicas de pesquisa utilizadas são a revisão bibliográfica e a análise quantitativa. Nossas conclusões levam a crer que a histórica desigualdade social e econômica tende a se elevar em um contexto no qual as decisões da sociedade são cada vez mais pautadas pelo valor de troca em detrimento do valor de uso, e quando a riqueza social é apropriada por poucos indivíduos do setor privado. Contradições latentes do capitalismo serão reforçadas com os desdobramentos políticos do país.
\end{abstract}

Palavras-chave: Espaço Urbano; Financeirização; Neoliberalismo; Emenda Constitucional.

\section{Abstract}

In this article we analyzed the impact of EC 95 on the urban financialization of the Brazilian economy. Special attention is given to the tendency of marketization of cities, at the same time that social rights and popular participation in the formulation of public policies can be reduced as a result of the deepening of neoliberalism in Brazil. For this analysis, we adopted the interdisciplinary methodology using studies from different fields. The research techniques used are bibliographic review and quantitative analysis. Our conclusions lead us to believe that social and economic historical inequality tends to rise in a context in which the decisions of society are increasingly based on exchange value rather than use value, and when few individuals of the private sector appropriate social wealth. Country political unfolding will enhance capitalism latent contradictions.

Keywords: Urban Space; Financialization; Neoliberalism; Constitutional Amendment. 


\section{Introdução}

A Emenda Constitucional número 95 (EC 95) aqueceu o debate público acerca do papel do Estado na economia e na promoção dos direitos sociais. Essa EC faz parte de um pacote de medidas que visam reequilibrar receitas e despesas da União, sendo que sua implementação pode comprometer o investimento nas áreas da saúde e da educação pelos próximos 20 anos. Além de reduzir os investimentos nessas áreas, a EC tem sido muito criticada por não ser acompanhada de medidas que alterem o sistema tributário regressivo vigente no país.

Não obstante os efeitos na saúde e na educação, essa EC, ao lado das demais medidas recém adotadas pelo governo federal, poderá impactar o planejamento e a gestão do espaço urbano, diante da redefinição do papel do poder público. As grandes metrópoles brasileiras, em especial a cidade do Rio de Janeiro, desde a década de go vêm sendo pensadas a partir da lógica do planejamento estratégico (VAINER, 2002). Nesse modelo, chamado por Harvey (2006) de "empreendedorismo urbano", os governos locais passam a adotar técnicas de gestão empresarial na sua atuação com vistas a garantir o sucesso da cidade mercadoria numa competição mundial entre grandes metrópoles a fim de atrair investimentos externos.

A ascensão do planejamento estratégico não pode ser compreendida sem se ter em consideração o processo de financeirização da economia, crescente desde a década de 1980 . No âmbito das cidades, acompanha-se a "apropriação progressiva e contraditória da renda fundiária pelos grandes grupos monopolistas" (LOJKINE, 1981). No Brasil, a financeirização urbana pode ser observada por meio da maior participação do mercado nos processos de rearranjo urbanístico como, por exemplo, por meio das Operações Urbanas Consorciadas, na flexibilização da legislação urbanística e da maior participação dos técnicos no planejamento urbano em detrimento da participação popular.

Nesse trabalho, tem-se como hipótese que um dos efeitos da EC 95 é a intensificação do processo de financeirização das cidades brasileiras e seus desdobramentos como a maior participação do mercado no planejamento e na gestão do espaço urbano.

Para a reflexão proposta, primeiramente, será apresentado o conceito de financeirização, no contexto do neoliberalismo, por intermédios dos seus principais expoentes no âmbito da macroeconomia, articulando tal prática à questão urbana tendo como referência os países centrais. Ainda na primeira seção, será realizada a relação entre a acumulação capitalista e o espaço urbano. Num segundo momento, será abordada a EC 95 e 
seus aspectos contraditórios e, por fim, serão apresentadas algumas considerações sobre os possíveis efeitos da EC 95 sobre o processo de financeirização urbana no Brasil.

Adota-se nesse artigo a metodologia interdisciplinar por meio da mobilização de autores de diferentes campos com o objetivo de lograr êxito em relação à problemática apresentada. As principais categorias teóricas são Neoliberalismo (HAYEK, 1983; HARVEY, 2005; FRIEDMAN, 2014), Financeirização (CHESNAIS, 1996; VAN DER ZWAN, 2014) e Espaço Urbano (LOJKINE, 1981; HARVEY, 2006). Utiliza-se aqui as técnicas de pesquisa de revisão bibliográfica e de análise quantitativa.

O artigo está dividido em três seções além dessa introdução. A seção 2 descreve o contexto em que a financeirização emergiu, define esse processo e o analisa sob a esfera das cidades; a seção 3 explicita a EC 95 enquanto apontando seus equívocos e o teor ideológico em sua essência. Termina essa seção apontando possíveis consequências sobre as cidades brasileiras; por fim, a seção 4 tece algumas considerações finais.

\section{Financeirização}

Neoliberalismo como solução para a crise de acumulação de capital

Após o fim da Segunda Guerra Mundial, países capitalistas desenvolvidos e em desenvolvimento testemunharam forte crescimento econômico. Esse crescimento foi caracterizado por uma distribuição mais igualitária ${ }^{1}$ dos ganhos econômicos: trabalhadores viram seus salários aumentarem e empresários se depararam com lucros crescentes (HOBSBAWN, 1995). Consequentemente, tanto a oferta quanto a demanda se expandiram.

A ampliação da participação do Estado na economia foi um traço desse período, cunhado de Estado de Bem-Estar Social (HOBSBAWN, 1995). Em síntese, o Estado fornecia uma rede de proteção para a sua população por meio de programas sociais de transferência de renda, como o seguro-desemprego e a previdência social. Também o governo realizava investimentos públicos, nos moldes propostos por Keynes²(1988).

1 Entre os anos de 1945 e 1970, a distribuição da renda nacional, em diferentes países, foi menos desigual do que a vista nos anos posteriores à 1970 (PIKETTY, 2014).

2 Keynes (1988) se tornou famoso ao propor, durante a crise capitalista dos anos 1929, um papel anticíclico do governo, isto é, quando a atividade econômica estivesse fraca, o Estado deveria aumentar o investimento público, o que contrabalancearia o fraco rendimento do setor privado. 
Esse período de expansão da atividade econômica, que durou, grosso modo, entre os anos 1945 e 1970, ficou conhecido como a Golden Age do capitalismo do século XX (ARRIGHI, 1994). O restante do século perderia o vigor econômico apresentado em sua metade, culminando em crescimento econômico mais fraco (SWEEZY, 2004). Essa Era de Ouro foi interrompida por um conjunto de fatores (Myrdal, 1977).

No ano de 1973, a Organização dos Países Exportadores de Petróleo (OPEP) empreendeu o primeiro choque do petróleo, quadruplicando o preço desse produto. Esse movimento foi sentido por diversos países, acarretando o encarecimento da produção das economias que eram dependentes do petróleo importado (ARRIGHI, 1994). O Brasil não foi exceção a essa regra (Hermann, 2011). O nível inflacionário, que se mostrava elevado durante a Golden Age, foi impactado desfavoravelmente. Outros fatores foram o endividamento e a redução do crescimento econômico dos países.

A dificuldade em superar essas adversidades forneceu condições para o surgimento de um amplo debate sobre quais políticas deveriam ser implementadas. A teoria que se saiu proeminente foi a que defendia a redução do tamanho do Estado, maior competição privada e crença no individualismo: o neoliberalismo ${ }^{3}$ (Harvey, 2005). O quadro institucional da Era de Ouro foi sendo desmantelado gradativamente, com o enfraquecimento de sindicatos, redução dos programas sociais e a construção de ambiente propício para negócios privados.

De acordo com Harvey (2005), as ascensões de Paul Volcker como comandante do banco central norte-americano em 1979, de Ronald Reagan como presidente dos Estados Unidos da América (EUA) em 1980 e de Margaret Thatcher como primeira ministra da GrãBretanha em 1979, foram eventos que impulsionaram a disseminação do neoliberalismo em escala global. Defensores dessa ideologia, tais como Hayek (1983) e Friedman $(2014)^{4}$, e o prêmio Nobel de Economia que ambos receberam, respectivamente, nos anos de 1974 e 1976, reforçou essa tendência. Por fim, o alastramento de defensores desse receituário

3 Nas palavras de Harvey (2005, pag. 5), o neoliberalismo "é uma teoria das práticas político-econômicas que propõe que o bem estar humano pode ser melhor promovido liberando-se as liberdades e capacidades empreendedoras individuais no âmbito de uma estrutura institucional caracterizada por sólidos direitos a propriedade privada, livres mercados e livre comércio".

4 Maiores detalhes sobre o pensamento desses autores podem ser vistos nos livros Os fundamentos da liberdade, de Hayek (1983), e Capitalismo e liberdade, de Friedman (2014). 
ocupando postos importantes em universidades, instituições e conselhos de empresas, significou o enraizamento dessa prática.

O neoliberalismo permitiu que o capital prosseguisse o processo de contínua reprodução e expansão. Se a crise de acumulação dos anos 70, por um breve instante, interrompeu essa trajetória, o neoliberalismo, ao abrir os mercados e ampliar o espaço de exploração do capital, propiciou um novo ciclo de acumulação. Esse desdobramento político, social e econômico confirma a proposição de que "o movimento do capital não tem limites" (MARX, 1968, pag. 171).

Circunscrito ao neoliberalismo e às políticas de abertura econômica que o caracteriza, há a política de abertura dos mercados financeiros. Segundo Chesnais (1996), a primeira fase da mundialização financeira, termo que o autor utiliza para ilustrar o atual funcionamento do capitalismo contemporâneo, ocorreu durante a Era de Ouro, quando o regime das finanças era controlado pelo Estado. Antes da crise dos anos 70, o excesso de poupança por alguns agentes pressionava por novos espaços de valorização do capital. A segunda fase foi a resposta a essa pressão e ao contexto de crise, as políticas de liberalização e desregulamentação financeira. A derradeira fase, a qual estamos vivenciando, é a abertura do mercado acionário, iniciada nos anos 9o. O gráfico 1 exibe essa fase de abertura financeira no tocante à economia brasileira, apresentando o fluxo de capital 5 em proporção com o produto interno bruto (PIB).

De 1970 a 1991, o fluxo de capital não atingiu a marca de 1\%, mas depois do ano de 1992, o ano de inflexão, ele cresce significativamente. Esse fluxo alcança 18\% em 1994 e tem um pico no ano de 2008 , com 32\%. Por meio desse gráfico, a experiência brasileira denota que a abertura do mercado acionário ocorreu, como traçado por Chesnais (1996), nos anos 90. Foram as políticas de abertura financeira iniciadas durante a presidência de Collor e aprofundadas por Fernando Henrique Cardoso.

Gráfico 1 - Fluxo de capital da economia brasileira

5 O fluxo de capital corresponde ao mercado de ações. Esse fluxo é composto por títulos públicos, títulos privados e ações de empresas. Também é conhecido como fluxo de portfólio. 


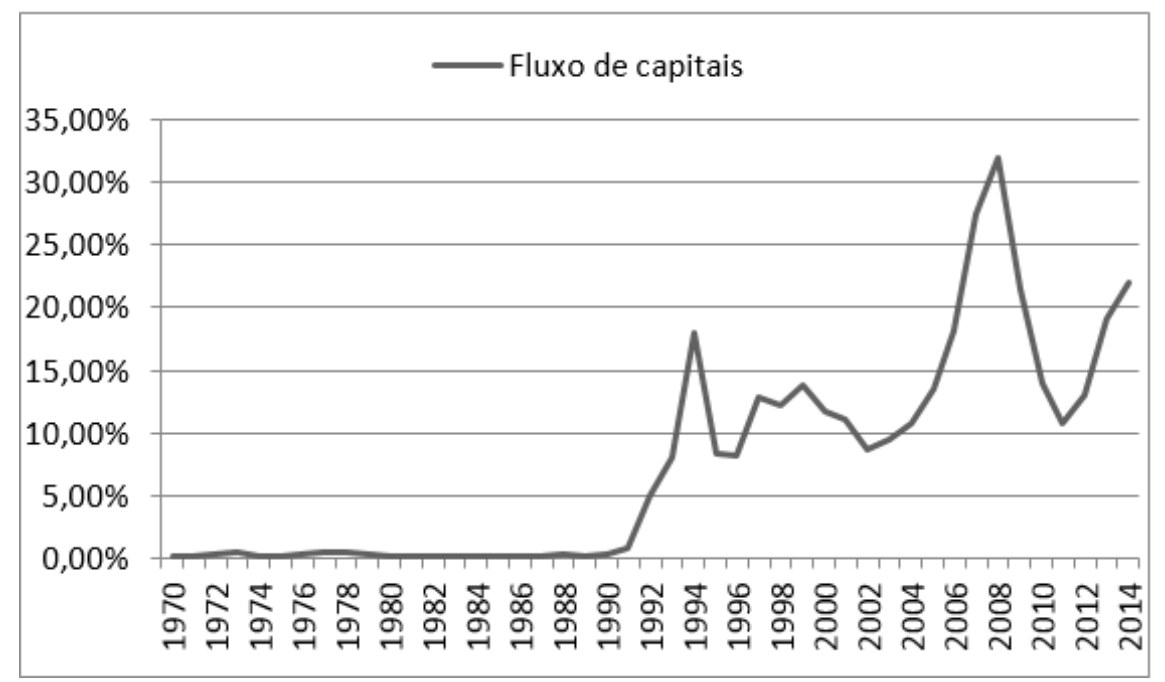

Fonte: Banco Central do Brasil e Banco Mundial

Tanto para a economia brasileira quanto para a economia mundial, a maior liberdade para os capitais explorarem novos territórios e espaços não deixou de acarretar alterações no modus operandi do capitalismo. A próxima subseção descreve uma dessas consequências, a financeirização.

\section{Financeirização}

De acordo com Van der Zwan (2014), financeirização pode ser entendida sob três ramificações: a maximização do valor do acionista (MVA), um novo regime de acumulação e a financeirização da vida cotidiana. Vale ressaltar que essas três dimensões do termo financeirização são inter-relacionadas, podendo tanto coexistirem quanto se influenciarem mutuamente.

Stockhammer (2004) e Lazonick e O'Sullivan (2000) denotam que a MVA representa uma inflexão no comportamento das empresas não-financeiras. Antes da ruptura da década de 1970, essas instituições visavam o horizonte de longo prazo, com planejamento de expandir a atividade produtiva e os empregos. Entretanto, com a liberalização financeira e o surgimento de novos canais de financiamento, essas empresas deslocaram o capital para o setor financeiro. Concomitantemente, os gerentes dessas corporações passaram a tomar decisões que seguissem o humor do mercado financeiro, pois isso atrairia novos investimentos para a firma, isto é, suas ações iriam se valorizar. A remuneração desses gerentes também foi alterada. Acoplado ao seu salário havia ações da própria empresa. Com 
isso, a valorização das ações acarretaria em maior remuneração para esses agentes. Por isso a denominação maximização do valor do acionista, dado que os gerentes visam valorizar as ações da empresa.

Mas a riqueza da sociedade, segundo Marx (1968), é proveniente da natureza e do trabalho. O deslocamento do capital para o setor financeiro, almejando ganhos financeiros de curto prazo, nada tem a dizer sobre o setor produtivo. Desse modo, duas consequências dessa alteração do modo operacional das firmas podem ser elencadas, o aumento do desemprego e queda dos rendimentos dos trabalhadores (Lazonick, 2012). O setor produtivo perde espaço frente ao setor financeiro nessa abordagem.

No tocante aos indivíduos, a abordagem da financeirização da vida cotidiana abrange esses agentes. Lapavitsas (2009) observa que conforme o Estado recuou na provisão de serviços sociais, esse espaço foi preenchido pelo setor financeiro. As famílias passam a comprar ativos financeiros para suprir necessidades fundamentais e garantir maior renda. Erturk et al (2005) chama essa tendência de democratização das finanças. Participar do mundo financeiro passa a ser visto como algo natural. Todavia, esse processo não está isento de riscos.

Como ilustrou a crise financeira dos EUA em 2007/2008, a disseminação de ativos financeiros pelas famílias de classe de renda baixa e média pode desencadear em riscos para todo o sistema. Em particular, as famílias norte-americanas detinham hipotecas do mercado subprime. Essa dívida que elas tinham com as instituições financeiras que emitiram o título foi transformada em outro ativo financeiro (securitização), e vendida para outros agentes. Desse modo, especulações ocorreram (DYMSKI, 2009). Chegou-se a um ponto no qual nem as autoridades reguladoras do sistema financeiro americano conseguiam compreender todo o esquema de transações.

Por fim, a crise atingiu principalmente os trabalhadores, culminando em elevado desemprego e perda de bens em decorrência de penhoras (LAPAVITSAS, 2011). Essa crise evidenciou a fragilidade da classe dos trabalhadores em um mundo cada vez mais financeirizado, no qual o afastamento do Estado e a privatização dos serviços públicos deslocaram essa classe para o setor financeiro. É a problemática entre a financeirização e a urbanização, tópico abordado na próxima subseção. O setor financeiro, por sua vez, aproveitou-se dessa conjuntura para extrair mais-valia dessas famílias. Porém, como é 
recorrente no capitalismo, os excessos da expansão do capital (especulação) terminam por gerar crises.

O último traço da financeirização é interpretá-la como um novo modo de acumulação de capital (Boyer, 2000). Na medida em que a acumulação pela via do setor produtivo se mostrou fraca nos anos 70, a solução foi o mercado financeiro. Arrighi (1994) afirma que essa é uma situação típica do capitalismo, na qual ciclos de crescimento se encerram com a expansão da atividade financeira. O autor aponta três ciclos na história do capitalismo, são eles: ciclo genovês, holandês e inglês. Estaríamos no quarto ciclo, relativo aos EUA, e na fase final, com as transações financeiras crescendo constantemente.

Para esse artigo, e dado o objetivo de compreender o eixo financeirização e urbanização, usaremos as abordagens da financeirização da vida cotidiana e financeirização como um novo modo de acumulação. Foge do nosso escopo analisar as empresas e o impacto delas sobre os indivíduos, embora seja uma temática relevante.

Sobre a financeirização da economia brasileira, Belluzzo e Almeida (2002) e Bruno et al (2009) afirmam que foi durante os anos 80 que esse processo se iniciou. Conforme o Brasil aprofundou o seu endividamento nesse período, e elevou a taxa de juros para combater a crescente inflação, os títulos públicos se tornaram atraentes para investidores. Por conseguinte, o rentismo na economia cresceu.

Paulani (2013), não obstante acate essa interpretação, denota que o Plano Real de 1994 foi outro fator que impulsionou as finanças na economia. O país tornou-se mais dependente do financiamento externo para poder crescer e se desenvolver. Em conjunturas nas quais o capital externo saía do país, a economia perdia ímpeto (RESENDE, 2005). Isso ilustra um traço da financeirização em nossa economia: o fato dos mercados financeiros influenciarem a elaboração de políticas públicas (HARVEY, 2016).

Pelo gráfico 1, visto na subseção anterior, percebemos a maior mobilidade do capital. Vale dizer que na composição do fluxo de capital, há títulos públicos. Desse modo, muito do capital que entrou no Brasil desde a abertura financeira é capital destinado a obter rendimento por meio do pagamento de juros. Chesnais (1996) assinala que a dívida pública é o ponto fundamental para compreendermos a crescente financeirização em escala mundial, 
e a história não parecer ser diferente para a economia brasileira ${ }^{6}$. É um canal pelo qual o capital se reproduz, obtendo mais-valia da população brasileira. Por fim, a EC 95, ao não direcionar qualquer medida relativa a esse meio de transferência de dinheiro público, colabora para o prosseguimento dessa dinâmica7.

\section{Financeirização e Cidades}

Para compreender a dinâmica da financeirização no âmbito das cidades, faz-se necessário, primeiramente, resgatar a abordagem sobre o espaço desde Karl Marx até seus principais interlocutores preocupados com a questão urbana, em especial, por intermédio dos estudos de David Harvey que, atualmente, é uma das principais referências do marxismo e da geografia urbana. A dimensão espacial da teoria da acumulação foi abordada por Marx, já no século XIX. Nas palavras de Harvey, ainda que de forma fragmentária e superficial, Marx conseguiu relacionar "o processo geral de crescimento econômico com o entendimento explícito de uma estrutura emergente de relações espaciais" (HARVEY, 2006, p.41).

Um primeiro aspecto importante para nossa abordagem é a compreensão do capital enquanto processo de circulação entre a produção e a realização (consumo), sendo fundamental para a acumulação que a circulação se expanda (HARVEY, 2006, p.71). A dimensão espacial desse processo, além de ser essencial para a expansão e para a acumulação, também assume papel central nas soluções para as crises do sistema de produção capitalista, neste caso, renovando as condições que possibilitam novos padrões de lucratividade ou se expandido para novas regiões. Mas, afinal, é possível determinar com precisão qual é o papel da urbanização no processo de acumulação?

Na década de 1980, Jean Lojkine afirmou que "as formas de urbanização são antes de mais nada formas de divisão social (e territorial) do trabalho" (LOJKINE, 1981, p. 121). Enquanto Manuel Castells (2014) considera o espaço urbano como lugar do consumo coletivo, Lojkine compreende o urbano como um elemento mais abrangente, que envolve

${ }^{6}$ Segundo Bruno et al (2009), a financeirização do Brasil é singular se comparada com os países desenvolvidos. Enquanto nesses a financeirização se iniciou pelo endividamento privado com baixa taxa de juros, no Brasil ela ocorreu pelo endividamento público com elevada taxa de juros.

$7 \mathrm{Na}$ seção 3 trataremos em maiores detalhes a EC 95. 
toda a relação de produção uma vez que "a esfera de produção, a da troca e a do consumo estão em constante interação" (LOJKINE, 1981, p. 139).

Importante destacar que Lojkine não compreende produção apenas como a fabricação material, mas sim como "a própria atividade que permite a reprodução da força de trabalho" sendo sua função social "tornar possível o consumo" (LOJKINE, 1981, p. 131). Logo, o urbano não está à margem do processo de produção, sendo que representa "o lugar da nova divisão do trabalho" (LOJKINE, 1981, p. 143).

David Harvey, ao resgatar as ideias de Karl Marx, aponta a necessidade da acumulação de minimizar os custos da circulação uma vez que "quanto mais longo o tempo de giro do capital, menor é o rendimento anual da mais-valia" (HARVEY, 2006, p. 48). A partir dessa necessidade, há aglomeração da produção em grandes centros urbanos, onde há também a anulação do espaço pelo tempo.

Jean Lojkine relaciona o fenômeno da apropriação monopolista da renda fundiária urbana às dificuldades relacionadas às ações de planejamento urbano uma vez que a supressão da propriedade privada monopolista é também, em última análise, a supressão do modo de produção capitalista. O autor pondera que a legislação só é capaz de expropriar o pequeno proprietário não dando conta da complexa relação entre capital monopolista e a renda fundiária, sendo que os grandes grupos econômicos passam a influenciar cada vez mais as ações de planejamento e gestão das cidades.

A apropriação da renda fundiária pelos grandes grupos monopolistas é um importante aspecto do processo de financeirização das cidades que, legitimado pelo discurso do neoliberalismo, tem se efetivado em diferentes metrópoles do mundo. No âmbito do espaço urbano, a financeirização se constitui enquanto práticas em que a própria cidade passa a ser concebida enquanto uma mercadoria.

Desde a crise do petróleo na década de 70, assim como o capitalismo, o planejamento e a gestão das cidades vêm se modificando para alcançar novos patamares de acumulação. Essas mudanças ocorrem no contexto já mencionado em que várias cidades do mundo são atingidas pela recessão do mercado e passam a conviver e compartilhar de problemas semelhantes como a desindustrialização e o desemprego. A perda de influência do EstadoNação favorece a um consenso de que a solução para a crise se dá pelo mercado por meio das privatizações e da abertura financeira. Nessa época, o empreendedorismo urbano surge enquanto discurso e prática que não se restringe ao âmbito dos governos, mas que mobiliza 
diversos atores em relações, muitas vezes, conflituosas, na tentativa de organizar o espaço (HARVEY, 2006, p. 169).

David Harvey, por meio dos estudos de caso acerca da cidade de Baltimore, nos Estados Unidos, apontou três características do empreendedorismo urbano. Primeiramente, destaca a noção de parceria público-privada como elemento principal desse novo modelo de governança. Por essa prática, os governos locais buscam a atração de fontes externas de financiamento bem como novos empreendimentos que possam gerar novos postos de emprego, acentuando, ainda mais, o poder da autoridade local na construção de estratégias para a expansão do capital (HARVEY, 2006).

Por fim, Harvey destaca a perda da importância da dimensão territorial das cidades por meio da "construção especulativa do lugar" uma vez que este torna-se o objetivo imediato do mercado ao invés da melhoria real das condições de moradia e de trabalho (HARVEY, 2006). Essa atuação com vistas a construção de uma imagem positiva das cidades acoberta muitos problemas sociais existentes ao revestir a cidade sob a atmosfera do dinamismo e da abertura econômica.

Para que essas mudanças no desenvolvimento das cidades ocorram, David Harvey aponta ainda quatro estratégias relativas ao empreendedorismo urbano. A primeira dessas estratégias decorre de um contexto de competição mundial entre as metrópoles (VAINER, 2002) e "significa a criação da exploração de vantagens específicas para a produção de bens e serviços" (Harvey, 2006, p. 172). Essa primeira estratégica relaciona-se com o conceito de renda monopolista a ser apresentado a seguir.

A segunda estratégia, também relacionada a supracitada competição, diz respeito ao destaque das cidades no âmbito do consumo por meio da regeneração urbana de espaços degradados e da criação de uma imagem na qual "a cidade tem de parecer um lugar inovador, estimulante, criativo e seguro para se viver" (HARVEY, 2006, p. 174). Destaca-se nesse âmbito o papel dos megaeventos culturais e esportivos como focos de investimento para promover a imagem das cidades.

Já a terceira estratégia decorre da necessidade do empreendedorismo em obter as "atividades de controle e comando referentes às altas finanças, ao governo à coleta de informações e ao seu processamento (incluindo a mídia)" (HARVEY, 2006, p.175). Para que esse novo padrão de governança tenha êxito, é essencial a construção de modernas 
infraestruturas de telecomunicação e transporte capazes de diminuir o tempo e o custos das transações.

Por fim, a quarta estratégia diz respeito a criação de uma vantagem competitiva em relação a distribuição dos recursos dos governos centrais. Harvey destaca que esses governos têm grande importância, sendo um mito a alegação de que não há mais repasse destes para os governos locais uma vez que muitos setores e regiões ainda dependem fortemente desses recursos (HARVEY, 2006).

Outro conceito para compreender o processo de financeirização das cidades é da renda de monopólio que "surge porque agentes sociais podem conseguir um maior fluxo de receitas por um maior período em virtude de seu controle exclusivo sobre determinado item [...] que em alguns aspectos cruciais, é único e irreproduzível" (HARVEY, 20,14, p. 172). A renda de monopólio é direta quando os bens monopolizados são diretamente comercializados e é indireta quando a mercadoria e/ou serviço decorrem do uso desses bens como, por exemplo, a renda proveniente da locação de um imóvel localizado numa área extremamente valorizada.

No contexto do empreendedorismo urbano, tem-se como objetivo que os processos de urbanização criem as rendas de monopólios tanto pela iniciativa privada quanto pelos governos locais (HARVEY, 2014, p. 191). Esse objetivo, contudo, não diz respeito apenas a criação de infraestruturas urbanas, mas relaciona-se também com aspectos da identidade cultural do próprio lugar.

Na busca pela criação da renda de monopólio, a prática do empreendedorismo urbano reforça a necessidade das cidades se destacarem no mercado global devido às suas peculiaridades. Conforme ressaltado por Harvey, "as alegações de singularidade, autenticidade, particularidade e especialidade (...) são tanto resultado das construções discursivas como dos conflitos baseados em fatos materiais" (HARVEY, 2006, p.232). Essas práticas, portanto, geram um capital simbólico coletivo que é apropriado de forma desigual pelos moradores das cidades.

Para melhor compreensão da renda de monopólio no âmbito das cidades, podemos tomar como exemplo a questão do turismo. Para que as cidades se destaquem nesse ramo, é necessário construir uma imagem positiva da cidade que reforce o diferencial desta em relação às demais. Aspectos históricos, tradição, belezas naturais, por exemplo, são evocados 
para se fazer a propaganda na cidade que compete com outras tantas na disputa pela atração de turistas e de investimentos externos.

Contudo, conforme ressalta David Harvey, a renda de monopólio não ocorre sem contradições. Com a chegada de novos investimentos e com o aumento da circulação de mercadorias e pessoas, essas cidades passam a compartilhar dos problemas globais: poluição, violência, segregação, grandes congestionamentos, a substituição do comércio local pelas grandes lojas multinacionais, entre outros. Ou seja, as singularidades que as tornavam um produto diferenciado nessa competição são camufladas por problemas e características comuns a todas as grandes metrópoles.

Portanto, resta demonstrado que o espaço urbano assume papel central na dinâmica da acumulação e que, recentemente, as cidades tentaram se tornar a saída para as crises do capitalismo. Contudo, as soluções propostas pelos entusiastas do empreendedorismo urbano deixam as cidades cada vez mais reféns do capital especulativo. O aumento da relevância do poder local possibilita que os governos locais negociem diretamente com investidores estrangeiros, aumentando a influência dos grandes grupos econômicos e as parcerias público-privadas passam a privilegiar os investimentos de riscos tornando o planejamento e a gestão do espaço urbano uma grande aposta. Conforme veremos na próxima seção, a emenda constitucional 95 tende a reforçar esse modelo de planejamento tendo em vista a diminuição do papel do Estado na provisão dos investimentos que garantem os direitos sociais consagrados constitucionalmente.

\section{EC 95}

Contas públicas e a EC

O presidente Michel Temer e sua equipe econômica se propuseram a resolver o desequilíbrio das contas públicas por meio da Emenda Constitucional número 95, anteriormente conhecida como PEC do teto de gastos. Essa EC é uma tentativa de disciplinar o gasto público, atingindo os Poderes Executivo, Judiciário, Legislativo, inclusive o Tribunal de Contas da União (TCU), Ministério Público da União e a Defensoria Pública da União.

A EC 95 limitará o crescimento das despesas primárias (gastos com educação, saúde, servidores, segurança, entre outros, com exceção dos gastos com o pagamento de juros da dívida) de determinado ano corrente com base na inflação do ano anterior. Para ilustrar esse 
mecanismo, um exemplo numérico será dado, com caráter apenas explicativo. Suponha que a despesa primária do ano de 2020 tenha sido de 100 bilhões de reais e a inflação desse mesmo ano de 10\%. De acordo com a EC, a despesa primária de 2021 não poderá ultrapassar o valor de 110 bilhões de reais (100 bilhões + 10\% de inflação). A inflação é o limite de crescimento dos gastos. Por isso diz-se que o gasto não poderá crescer em termos reais. Em caso de descumprimento dessa regra, a EC prevê medidas corretivas para o ano subsequente ao do exercício, como a proibição de concursos públicos e o congelamento de subsídios.

Antes de prosseguirmos na análise, apresentaremos duas equações relativas às contas públicas. A equação (1) retrata as contas primárias. É o objetivo da $E C$, isto é, reduzir a despesa primária. Quando a receita primária é superior à despesa primária, diz-se que o país obteve superávit primário (1.1). O caso inverso, quando a despesa é superior às receitas, dizse déficit primário (1.2). Observe que o resultado primário está presente na equação (2). Essa equação nos mostra o resultado nominal. Ela incorpora a equação (1) e acrescenta o pagamento de juros da dívida. Quando o resultado primário é superior ao pagamento de juros, o país gerou superávit público (nominal) (2.1). Em situação oposta, diz-se que o país gerou déficit nominal (2.2). Em última instância, esse é o objetivo principal da EC, tornar o país gerador de superávits públicos (ou seja, obter resultados similares às equações 1.1 e 2.1), mas modificando a despesa primária para isso (equação 1). Vale ressaltar que, ainda que o país obtenha superávits primários (equação 1.1), isso pode representar déficits nominais (equação 2.2), pois o resultado nominal depende do resultado primário e do pagamento de juros (equação 2). Observe que a EC impactará somente o primeiro componente, isto é, o resultado primário.

resultado primário $=$ receita primária - despesa primária superávit primário $=$ receita primária $>$ despesa primária déficit primário = receita primária $<$ despesa primária

resultado nominal $=$ resultado primário - pagamento de juros superávit nominal $=$ resultado primário $>$ pagamento de juros déficit nominal $=$ resultado primário $<$ pagamento de juros 
Vamos aos dados. O gráfico 2 exibe a receita primária e a despesa primária do governo central em proporção com o produto interno bruto (PIB). Como dito acima, tanto a receita quanto a despesa primária excluem os juros. Estamos analisando, portanto, a equação (1). A EC é direcionada a disciplinar os gastos primários. Observe que em todo o período de 1998 a 2013 a receita foi superior à despesa. Nessa situação, afirma-se que o país gerou superávits primários (equação 1.1). Desse modo, voltando às equações (1) e (2), o Brasil cumpriu a primeira parte do ajuste fiscal, que é apresentar superávit primário (equação 1). Resta avaliar se a equação (2) também seguiu essa tendência.

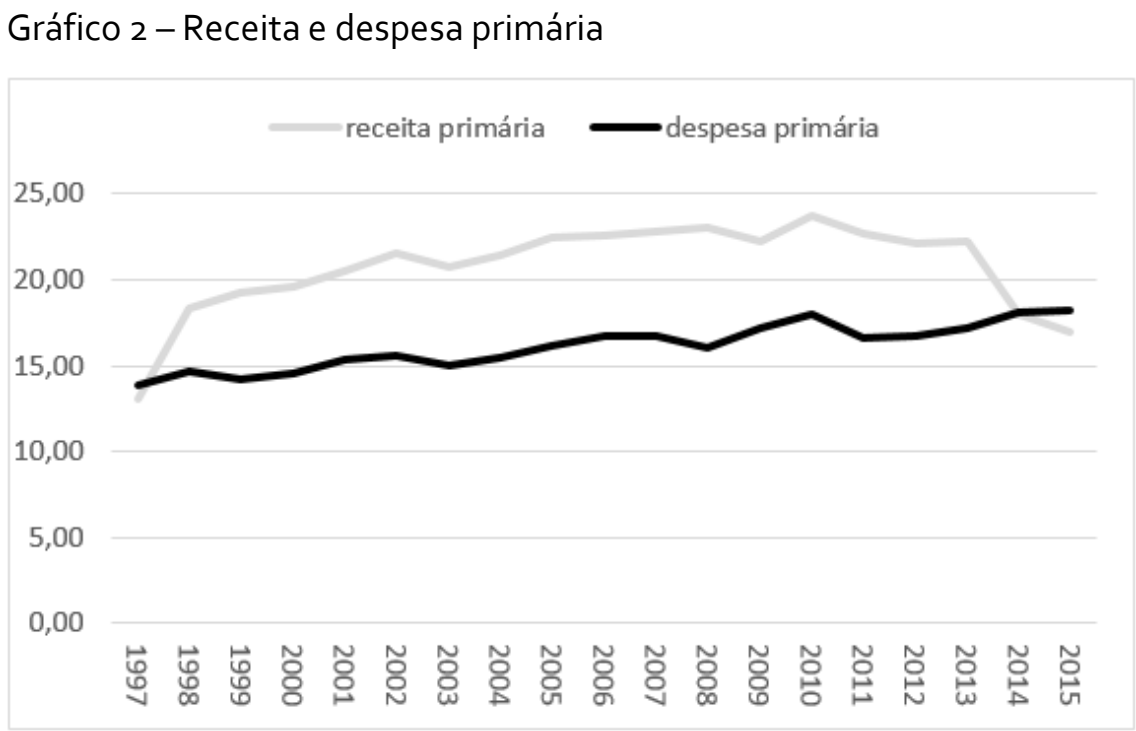

Fonte: Tesouro e IBGE

A crise econômica em que a economia brasileira entrou desde 2014 fez com que a receita caísse, impactando negativamente nos anos de 2014 e 2015. Isso explica a queda da receita primária no gráfico 2. A EC responsabiliza os gastos primários pelo desajuste fiscal, mas esses gastos estiveram em patamar inferior à receita em quase todos os últimos anos.

O gráfico 3 apresenta o resultado primário (receita primária menos despesa primária) e o pagamento de juros da dívida, ambas as variáveis em proporção com o PIB. É a equação (2). Sobre o resultado primário, vimos no gráfico 2 que o país gerou superávits primários por vários anos. A inclusão do pagamento de juros nos permite inferir sobre o resultado nominal, que é a inclusão do pagamento de juros sobre o resultado primário (equação 2). Veja que em todo o gráfico 3 o pagamento de juros é superior ao superávit primário (equação 2.2). É uma situação de déficit público (gráfico 4). 
Por meio do gráfico 4, podemos concluir que o Brasil apresentou déficits públicos em todos os anos, embora tenha realizado superávit primários. Na maior parte dos anos a despesa primária não foi um problema para as contas públicas, ela se manteve, em geral, em patamar inferior à receita primária.

Gráfico 3-Resultado primário e pagamento de juros

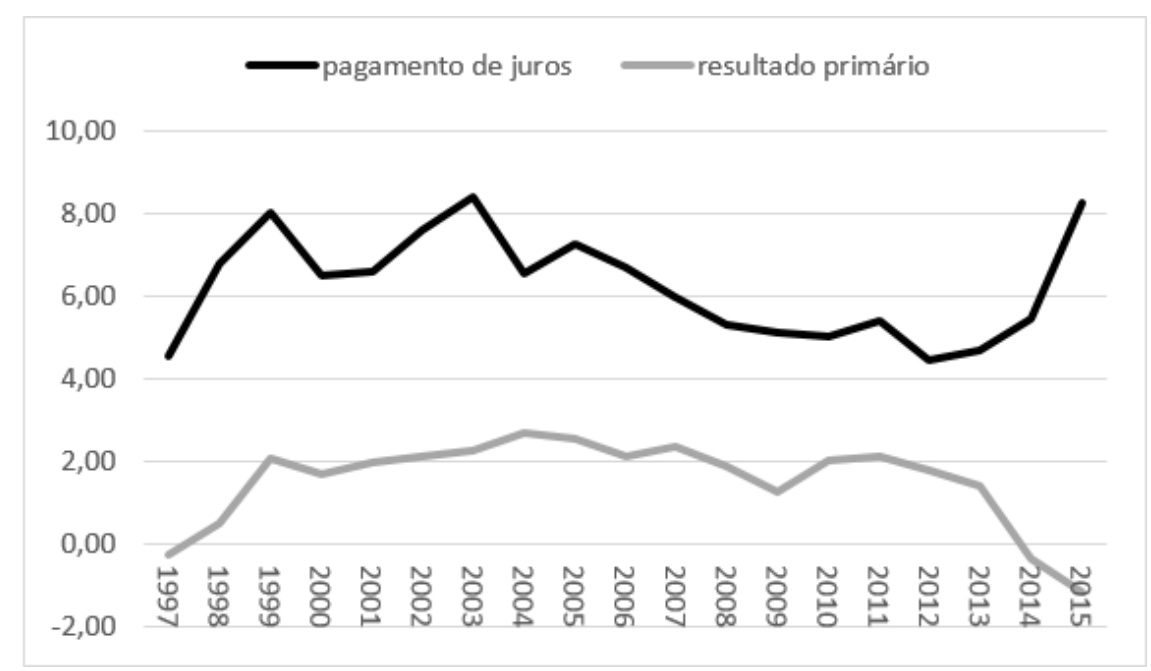

Fonte: Banco central, Tesouro e IBGE

A EC 95, ao ignorar esse fato, apresenta grave erro de interpretação das contas públicas. Não ignoramos os efeitos do não pagamento dos juros, pois a experiência nos mostra que países que adotaram essa medida sofreram perdas significativas de financiamento (DIAZ-ALEJANDRO, 1985; BELLUZZO; ALMEIDA, 2002). A EC apenas se limita a dizer que, conforme o ajuste fiscal for bem-sucedido, acarretará a queda estrutural da taxa de juros. Com isso, o pagamento de juros tenderia a decrescer. Esse raciocínio ignora, como vimos no gráfico 2, os anos de 1998 a 2013, quando o país apresentou receita primária superior à despesa primária. E mesmo com esse resultado, o pagamento de juros da dívida não permitiu que a economia apresentasse superávit público (gráfico 3, equação 2.1). Houveram déficits fiscais em todos os anos (gráfico 4), independentemente do resultado primário positivo.

Gráfico 4-Déficit público/PIB 


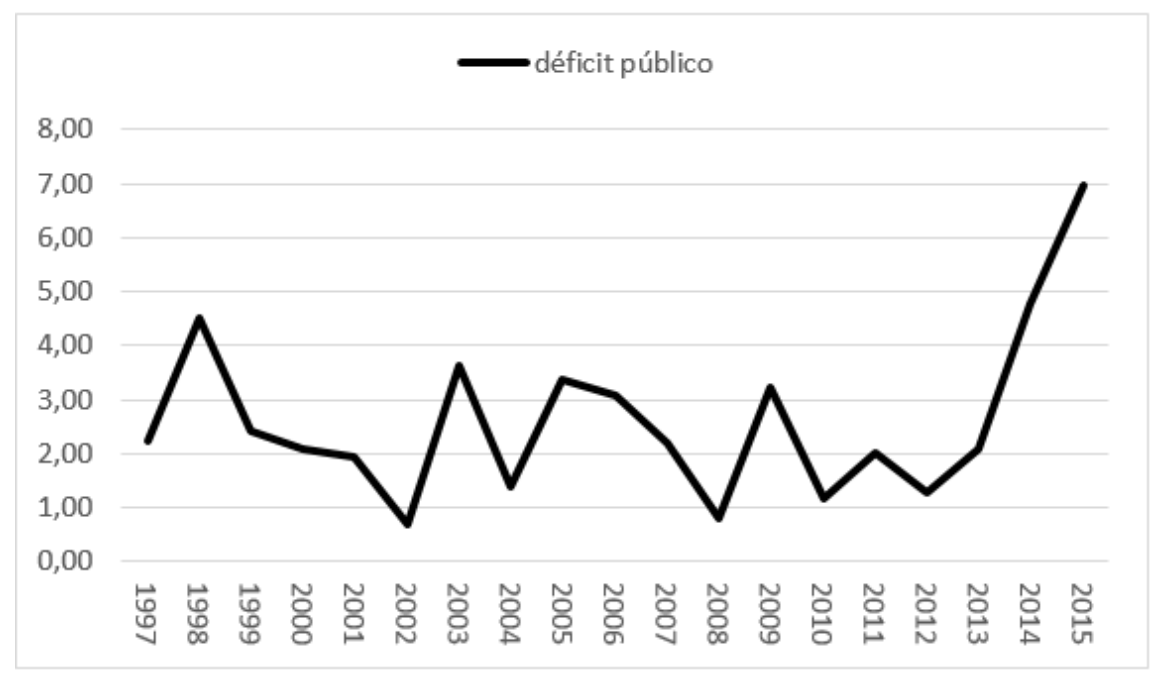

Fonte: Tesouro e IBGE

No arcabouço macroeconômico da Ciência Econômica, há mecanismos que poderiam reduzir o pagamento de juros da dívida, ao mesmo tempo combatendo a inflação ${ }^{8}$. Um deles é o aumento do depósito compulsório (MANKIW, 2011). Esse mecanismo obriga bancos comerciais e instituições financeiras a depositarem parte de suas reservas junto ao banco central. É o banco central quem determina o patamar desse depósito. Maiores taxas de depósito reduzem o capital disponível para essas instituições realizarem operações, logo, tanto o crédito quanto o investimento são reduzidos. A vantagem, comparada com a política de elevar a taxa de juros, é que o pagamento de juros da dívida não seria afetado, uma vez que é a taxa de juros Selic que afeta a remuneração dos títulos públicos. Deste modo, o banco central poderia reduzir a taxa de juros Selic, o que faria diminuir o pagamento de juros da dívida9 ${ }^{9}$ ao mesmo tempo elevando a taxa do depósito compulsório, o que combateria a inflação. Entretanto, essa estratégia não é considerada pela EC.

Não defendemos exatamente essa estratégia para a economia brasileira, visamos ilustrar que há outros caminhos que poderiam ser adotados. Questionamos, entretanto, a

8 O banco central utiliza a taxa de juros Selic para combater o aumento dos preços no país. Um elevado patamar de juros encarece o crédito no país, reduzindo tanto o investimento produtivo quanto o consumo. Consequentemente, os preços tendem a decrescer. Há vários críticos a respeito dessa estratégia de combater a inflação utilizando a taxa de juros. Um dos pontos questionados é que, ao subir o nível da taxa de juros, o pagamento de juros da dívida pública é aumentado, pois parte dessa dívida é indexada à taxa de juros. Ademais, alto nível de juros incentiva práticas rentistas. Os trabalhos de Carvalho (2016) e Contri (2014) retratam esses pontos.

9 De acordo com dados do Tesouro (2016), 40\% de toda a dívida pública é indexada à taxa de juros Selic. 
omissão da EC 95 em relação ao pagamento de juros da dívida pública. Essa situação está em consonância com a afirmação de que estamos em um "regime de ditadura dos credores" (CHESNAIS, 1996, pag. 30). Nesse caso, em particular, credores seriam os rentistas, as instituições financeiras e a elite financeira ${ }^{10}$ (PAULANI, 2013; DOWBOR, 2016).

Outro ponto suscetível de críticas são os gastos direcionados para a saúde e educação. Os defensores da EC argumentam que os ganhos de eficiência no uso do dinheiro público compensarão eventuais cortes de gastos nessas áreas. É questionável esse ponto. É fato, porém, que o nosso gasto per capita na saúde é insuficiente, e que o sistema público de saúde é ofertado em nível inadequado frente às demandas da população (COLLUCCI, 2016). E, apesar dos avanços recentes nos indicadores educacionais, o país está distante do nível de escolaridade de países desenvolvidos (FOLHA, 2016).

Por fim, um dos pontos que motivaram a EC 95 é o fato de que a despesa primária cresceu acima do nível da inflação por vários anos, e que isso terminaria em resultar em crise fiscal. O gráfico 5 apresenta o crescimento anual em porcentagem da despesa primária e o nível da inflação para cada ano. Essa afirmação é corroborada por esse gráfico: a despesa primária, de fato, se expandiu acima da inflação. Todavia, vimos também que a receita primária foi superior a essa despesa em vários anos (gráfico 2 ) e que, apesar da geração de sucessivos superávits primários, o elevado pagamento de juros da dívida impediu que superávits públicos ocorressem (gráficos 3 e 4). Ademais, consideramos pouco razoável limitar gastos essenciais, como os da educação e saúde, em um país que necessita de se desenvolver e enfrentar profundas desigualdades sociais e econômicas. Basta uma rápida análise em dados como os do IPEA (2016) para verificar tais informações, que retratam que o grupo dos $10 \%$ mais ricos do país detém $40 \%$ de toda a riqueza nacional, enquanto o grupo dos $20 \%$ mais pobres possui $3,5 \%$ dessa riqueza ${ }^{11}$.

Gráfico 5: Crescimento da despesa e inflação

\footnotetext{
${ }^{10} \mathrm{O}$ atual presidente do banco central (BACEN), Ilan Goldfajn, trabalhava no Itaú Unibanco, uma instituição financeira, antes de tomar posse como comandante do BACEN. Bin (2015) cita vários casos semelhantes a esse.

${ }^{11}$ Esses dados são relativos ao ano de 2014. Em 1981, por exemplo, os 10\% mais ricos detinham 46,4\% da riqueza nacional, e os $20 \%$ mais pobres $2,66 \%$. Isso denota que a desigualdade econômica tem reduzido ao longo dos anos, mas que resta um longo trajeto para percorrer.
} 


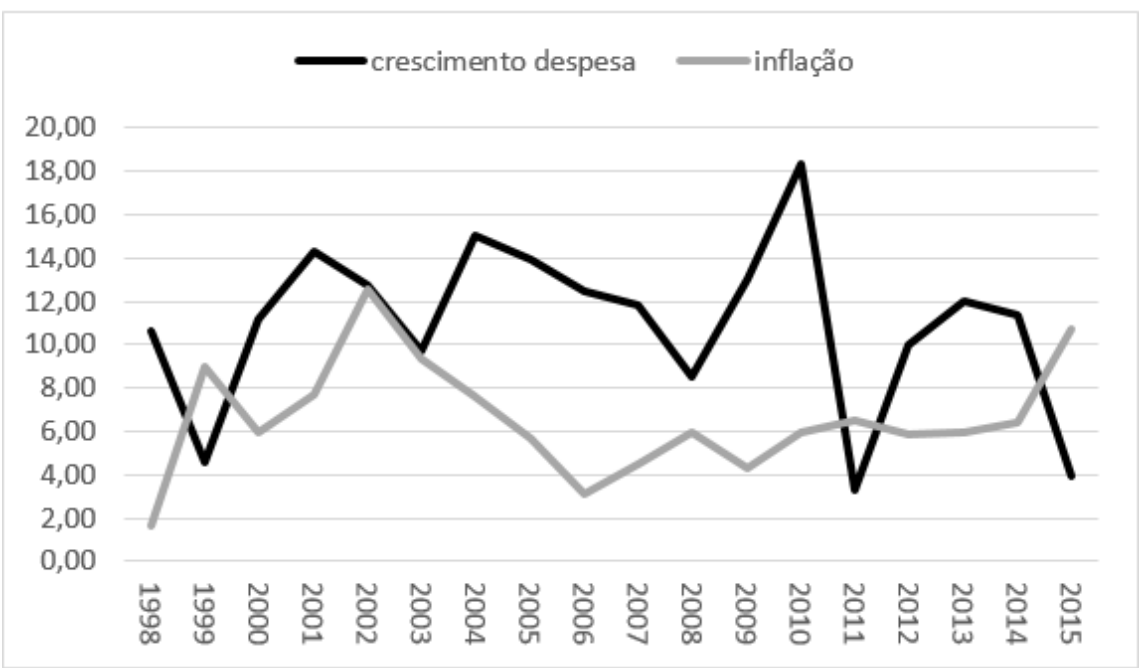

Fonte: Tesouro e IPEA

Interpretamos a EC 95 como um mecanismo para retirar o Estado da provisão de serviços públicos e fornecer espaço para a expansão do capital pelo setor privado. Assim como ocorreu nos anos 80 com os EUA e a Grã-Bretanha, a EC pode representar um impulso para o alastramento da financeirização no Brasil. Conforme as famílias tenham de utilizar serviços financeiros para suprir suas necessidades, isso representaria o avanço do setor financeiro em áreas antes supridas por programas públicos. É um mecanismo de extração de mais-valia que pode se propagar na economia brasileira. Ademais, todo esse processo está circunscrito na problemática urbana do país, que é tratada na próxima subseção ${ }^{12}$.

Os possíveis impactos da EC sobre as cidades

Feitas as necessárias ponderações acerca da EC 95, desmistificando, inclusive, alguns dos argumentos que tentam legitimar tais medidas, destacamos quais são os seus possíveis impactos em relação às cidades brasileiras. Para essa abordagem, contudo, faz-se mister, primeiramente, ressaltar as peculiaridades do nosso processo periférico de urbanização.

Na década de 70, Lúcio Kowarick analisou o processo de urbanização das cidades brasileiras tendo como referência empírica a Grande São Paulo, ressaltando que o alto desempenho econômico da região à época não significava, necessariamente, em aumento

\footnotetext{
${ }^{12}$ Outras alternativas para o ajuste fiscal poderiam ser uma reforma tributária, combate aos supersalários do setor público, maior fiscalização dos beneficiários de dinheiro público, tributação sobre ganhos com o capital e grandes fortunas, entre outras. Há uma ampla gama de possíveis caminhos.
} 
da qualidade de vida, sendo as nossas cidades consequências diretas do nosso modelo de desenvolvimento econômico (KOWARICK, 1979).

Por meio desse estudo, Lucio Kowarick desenvolveu o conceito de espoliação urbana enquanto expressão de um padrão periférico de urbanização. Segundo Kowarick, "a lógica da acumulação que preside ao desenvolvimento brasileiro recente apoia-se exatamente na dilapidação da força de trabalho" (KOWARICK, 1979, p. 42). A espoliação possuiria duas dimensões. Primeiramente, se manifesta por meio da condição de exploração brutal do trabalho uma vez que o salário só remunera a tarefa e não as condições de reprodução da força de trabalho. A segunda dimensão diz respeito a precariedade do conjunto de serviços (bens de consumo coletivo) essenciais à reprodução da força de trabalho. Dada essas condições, surge a necessidade de "sobretrabalho", na qual o trabalhador, por ele mesmo, passa a garantir os meios da sua reprodução, gerando a "acumulação por espoliação" (KOWARICK, 1979). A autoconstrução nas periferias é um exemplo no qual o trabalhador arca com os custos da sua sobrevivência.

A limitação das despesas primárias proposta pelo supracitado projeto de emenda constitucional impactará na garantia dos direitos sociais de grande parte da população que necessita do Estado para ter acesso à diversos bem materiais e imateriais. Caso aprovada, a EC poderá gerar efeitos negativos na promoção dos direitos sociais consagrados constitucionalmente como a saúde, educação e moradia, por exemplo, uma vez que, pelo período de 20 anos, não se poderá gastar além do mínimo estipulado pela emenda. Essa medida favorece a intensificação da exploração das classes trabalhadoras que não poderão contar com o Estado para terem satisfeitas as suas necessidades elementares por meio da provisão dos bens de consumo coletivo. Numa realidade em que o salário mínimo não comporta todas as necessidades básicas das famílias brasileiras como, por exemplo, a moradia adequada, o acesso aos direito sociais será comprometido. ${ }^{13}$

Esse primeiro e importante aspecto tem impacto direto na vida cotidiana dos brasileiros. A falta de investimentos suficientes na garantia dos direitos sociais tende a agravar a nossa desigualdade social e econômica que é histórica e estrutural. Nas cidades,

\footnotetext{
13 De acordo com estimativa feita pelo Departamento Intersindical de Estatística e Estudos Socioeconômicos, no mês de outubro de 2016, o salário mínimo necessário deveria ter o valor de $\mathrm{R} \$$ 4.016,27. Disponível em http://www.dieese.org.br/analisecestabasica/salarioMinimo.html Acesso em o4 out. 2016.
} 
onde as diferenças de acesso aos benefícios da urbanização podem ser verificadas por meio do contraste entre os diferentes lugares que habitam as populações mais ricas e mais pobres, a segregação socioespacial irá reforçar os espaços de exclusão, seja tanto pelo isolamento das classes mais altas quanto pelo abandono das áreas habitadas pela população mais carente.

No âmbito do planejamento e da gestão urbana, a nova conjuntura cristalizada pela EC poderá reforçar os preceitos do empreendedorismo urbano que mercantiliza, cada vez mais, as relações no espaço urbano uma vez que, no âmbito das cidades, o projeto neoliberal impacta decisivamente na condução da política urbana (SOUZA, 2015).

A influência neoliberal no planejamento e na gestão das cidades é constatada pela recorrência às parcerias público-privadas para financiar empreendimentos urbanos. Um dos instrumentos muito utilizados pelos governos (federal, estaduais e municipais) é a operação urbana consorciada (OUC). Consagrada no Estatuto da Cidade promulgado em 2001, a OUC é o conjunto de medidas e intervenções coordenadas pelo poder público em parceria com agentes privados. A finalidade da OUC é promover, em determinada área, transformações estruturais, melhorias sociais e valorização ambiental.

A arquiteta e urbanista, Mariana Fix (2003), observa com ressalva esse instrumento. Para ela, a consagração da operação urbana consorciada, além de fortalecer um discurso questionável de que falta recursos públicos para se investir em políticas urbanas, incorpora as parcerias público-privadas no âmbito do planejamento e da gestão urbana. Para além de toda crítica acerca da simbiose entre o Estado e o mercado no contexto do neoliberalismo, as operações urbanas invertem a lógica do planejamento público uma vez que o mercado é quem passa a determinar onde serão as áreas afetadas pelos empreendimentos, de acordo com os interesses privados do mercado. A valorização e os benefícios decorrentes das obras dessa parcerias público-privadas são restritas aos locais escolhidos estrategicamente pelos parceiros do Estado.

A crítica a esse instrumento, aliada ao fato de que, no contexto do empreendedorismo urbano os projetos executados pelo Estado e pelo mercado, conforme destacado na seção anterior, assumem os risco do mercado, reforçam ainda mais a construção de cidades voltadas para atender aos interesses especulativos do mercado e não as necessidades reais da população de acesso aos direitos sociais, uma vez que esses empreendimentos, ao invés de buscar a melhoria da qualidade de vida das pessoas, tende a reforçar o caráter 
mercadológico das obras realizadas pelos governos municipais em parceria com o poder privado. Portanto, além de comprometer os direitos sociais, a EC, ao congelar as despesas primárias, de certa forma, ratifica a solução para manter os investimentos em infraestrutura urbana pela via do mercado.

O congelamento dos investimentos públicos na área social tende a reforçar a alternativa do empreendedorismo urbano de que as cidades gerem as suas próprias riquezas por meio do marketing urbano que transforma a própria cidade em mercadoria (VAINER, 2002). Ao promover a imagem local para atrair investimentos externos, conforme já problematizado no item anterior, experimenta-se as contradições da renda de monopólio. Além disso, no processo de mercantilização das cidades, o planejamento e a gestão do urbano passam a privilegiar mais o valor de troca dos equipamentos urbanos do que o valor de uso, contradição intrínseca do capitalismo, desmembrada no trabalho de Marx (1968). Conforme o valor de troca se torna proeminente, o valor de uso perde espaço no processo de produção: a preocupação pauta-se em produzir cada vez mais com o objetivo da realização de lucros e não para atender às necessidades da população. Surge um crescente hiato entre os valores de troca e de uso. Logo, o acesso aos bens coletivos é restrito a quem pode pagar pelo produto caro que é a cidade no contexto neoliberal (VAINER, 2002).

Os possíveis efeitos da emenda constitucional apresentados aqui têm como principal eixo a intensificação das políticas neoliberais sinalizadas pelas atuais medidas políticas e econômicas do governo Temer. O processo de financeirização da cidade ganha força num cenário em que o Estado passa a limitar seus investimentos nos direitos sociais e o mercado passa a determinar, de forma mais contundente, o planejamento e a gestão das cidades.

Esse processo deve ser compreendido numa conjuntura de constantes crises que, desde a década de 70, tem reforçado o papel do espaço urbano na recuperação da economia de mercado ao proporcionar, por meio da construção, destruição e reconstrução das cidades, novos patamares de acumulação.

O empreendedorismo urbano, nesse contexto, é forjado enquanto discurso e prática que, além de atribuir ao poder local papel protagonista na geração de mais riquezas, insere o mercado no planejamento e na gestão das cidades de maneira direta e que subjuga tais ações aos interesses especulativos, tudo isso com o apoio do Estado.

Outra estratégia do empreendedorismo urbano é reforçar a singularidades das cidades a fim de gerar rendas monopolistas, apropriadas, muitas vezes, por poucos 
investidores enquanto as contradições dessa opção são compartilhadas por todos os moradores da cidade, conforme ressaltado na seção anterior. Essa é outra contradição do capitalismo enfatizada por Marx (1968). A riqueza produzida é social, envolve a colaboração de diferentes trabalhadores para o seu surgimento, todavia, a apropriação dela ocorre por poucos indivíduos do setor privado. Essa lógica aprofunda a desigualdade de renda, culminando na concentração e centralização do capital em pequenos grupos.

Nessa conjuntura, a participação popular no planejamento e na gestão do espaço urbano é enfraquecida sendo maior a influência do mercado na condução da política urbana que age de acordo com as necessidades especulativas. Essa situação compromete ainda a efetivação do princípio da gestão democrática das cidades consagrado no Estatuto da Cidade de 2001.

A intensificação do neoliberalismo apontada pela atual conjuntura brasileira, portanto, tende a dificultar o acesso aos direitos sociais de grande parte da população e a intensificar a exploração dos trabalhadores que não poderão contar com os investimentos do Estado para garantir a sua reprodução. Esse cenário prejudica o acesso aos bens coletivos do espaço urbano e aponta a consolidação de cidades ainda mais segregadas e excludentes.

\section{Conclusão}

Esse artigo analisou possíveis impactos da EC 95 sobre a financeirização urbana do Brasil. Inicialmente descrevemos a difusão da financeirização em escala mundial para posteriormente delimitar esse processo na economia brasileira. O espaço urbano tende a excluir determinados indivíduos, em geral de renda baixa, para a ascensão, consolidação e reprodução do capital privado. Como é historicamente visto, o capital apresenta flexibilidade para se adequar a diferentes contextos, buscando superar conjunturas de baixa lucratividade.

As atuais medidas e reformas que o governo federal têm adotado se relacionam com as implementadas pelos governos de Thatcher e Reagan na década de 1980. Não é mera coincidência, é o empreendimento deliberado de um projeto que defende a limitação do Estado e concede maior liberdade para o capital explorar novos espaços. É o reforço do individualismo, da propriedade privada e da liberdade econômica, tópicos consagrados nos trabalhos de Hayek e Friedman. 
Com o benefício da análise retrospectiva, vemos que nos EUA a desigualdade de renda tem crescido desde os anos 1980, período das reformas neoliberais. Esse fato pode ser um prelúdio para o que testemunharemos nos próximos anos no Brasil. Englobando o Reino Unido na análise, ambos os países anglo-saxônicos apresentaram significativo aprofundamento da financeirização a partir das políticas neoliberais. Esse pode ser um ponto de inflexão para a nossa sociedade no tocante a esse processo.

As cidades podem ter os seus níveis de exclusão social incrementados com o conjunto das medidas do atual governo. Os impactos da guinada das políticas públicas pró-mercado não são irrelevantes. Conforme o valor de troca se torna proeminente em detrimento do valor de uso, necessidades básicas da população podem deixar de ser atendidas, haja vista o recuo do Estado na provisão de serviços sociais. Da mesma forma, a apropriação da riqueza social por grupos de indivíduos privados incrementa não somente a desigualdade econômica, como também alimenta um sentimento de revolta pela população. Todavia, a adversidade também abre espaço para oportunidades: tais contradições inerentes ao capitalismo e aprofundadas pelas atuais políticas, apesar de representarem um regresso aos avanços sociais recentes, podem desencadear a união de uma esquerda fragmentada para enfrentar o atual cenário político e propor novos caminhos para o país.

\section{Referências}

BELLUZZO, L. G. e ALMEIDA, J. Depois da Queda: A Economia Brasileira da Crise da Dívida aos Impasses do Real. Rio de Janeiro: Civilização Brasileira, 2002.

BOYER, R. Is a Finance-Led Growth Regime a Viable Alternative to Fordism? A Preliminary Analysis. Economy and Society, v. 29, n. 1, p. 111-145, 2000.

BRUNO, M.; DIAWARA, H.; ARAÚJO, E.; REIS, A.; RUBENS, M. Finance-Led Growth Regime no Brasil: Estatuto Teórico, Evidências Empíricas e Consequências Macroeconômicas. Texto para discussão, n. 1455, IPEA, 2009.

CASTELLS, M. A questão urbana. Rio de Janeiro, Editora Paz e Terra, 2014.

CARVALHO, F. Looking into the abyss? Brazil at the mid-2010s. Journal of Post-Keynesian Economics, v. 39, p. 93-114, 2016.

CHESNAIS, F. A Mundialização do Capital. São Paulo: Xamã, 1996.

COLLUCCI, C. Ajuste fiscal "corta a carne" dos pobres, mas deixa ricos intocados. [S.I.], 2016.

Disponível em: http://www1.folha.uol.com.br/colunas/claudiacollucci/2016/10/1821863-ajuste-fiscalcorta-a-carne-dos-pobres-mas-deixa-ricos-intocados.shtml. Acesso em 12 out. 2016. 
CONTRI, A. Uma Avaliação da Economia Brasileira no Governo Dilma. Indicadores Econômicos FEE, v. 41, n. 4, p. 9-20, 2014.

DIAZ-ALEJANDRO, C. F. Goodbye Financial Repression, Hello Financial Crash. Journal of Development Economics, v.19, n. 1, pp. 1-24, 1985.

DOWBOR, L. "A economia travada pelos intermediários financeiros." In: SADER, E. (Org.). O Brasil que queremos. Laboratório de políticas públicas da Universidade do Estado do Rio de Janeiro, 2016.

DYMSKI, G. A. Financial Risk and Governance in the Neoliberal Era. In: CLARK, G. L, DIXON, A. D. e MONK, A. H. (Orgs.). Managing Financial Risks, From Global to Local: Oxford University Press, 2009.

ERTURK, I.; FROUD, J.; JOHAL, S.; LEAVER, A.; WILLIAMS, K. The Democratisation of Finance? Promises, Outcomes and Conditions. University of Manchester. Working Paper, n. 9, 2005.

FIX, M. A "Fórmula mágica" da "parceria": operações urbanas em São Paulo. São Paulo, FAU/USP, 2003. Disponível em:

http://www.usp.br/fau/depprojeto/labhab/biblioteca/textos/fix_formulamagicaparceria.pdf 1.

Acesso em 13 out. 2016.

FOLHA, Editorial. São Paulo, 2016. Disponivel em:

http://www1.folha.vol.com.br/opiniao/2016/02/1738194-atraso-na-educacao.shtml. Acesso 11 fev. 2016.

FRIEDMAN, M. Capitalismo e liberdade. São Paulo: LTC, 2014.

HARVEY, D. O neoliberalismo: história e implicações. São Paulo: Edições Loyola, 2005.

HARVEY, D. A produção capitalista do espaço. São Paulo: Editora Annablume, 2006.

HARVEY, D. Cidades Rebeldes. São Paulo: Martins Fontes, 2014.

HARVEY, D. 17 contradições e o fim do capitalismo. São Paulo: Boitempo, 2016.

HAYEK, F. Os fundamentos da liberdade. São Paulo: Visão, 1983.

HERMANN, J. Auge e Declínio do Modelo de Crescimento com Endividamento: O II PND e a Crise da Dívida Externa (1974-1984). In: GIAMBIAGI, F.; VILLELA, A.; CASTRO, L.; HERMANN, J. (Orgs.).

Economia Brasileira Contemporânea. Elsevier, 2011.

HOBSBAWM. E. Era dos Extremos. São Paulo: Companhia das Letras, 1995.

Instituto de Pesquisa Econômica Aplicada (IPEA). [S.I., (2016?)]. Disponível em:

http://www.ipeadata.gov.br/Default.aspx. Acesso em: 22 nov. 2016.

KEYNES, J. M. A Teoria Geral do Emprego, do Juro e da Moeda. São Paulo: Nova Cultural, 1998.

KOWARICK, L. A espoliação urbana. São Paulo: Paz e Terra, 1983.

LAPAVITSAS, C. Financialised Capitalism: Crisis and Financial Expropriation. Historical

Materialism, v. 17, p. 114-148, 2009. 
LAPAVITSAS, C. Theorizing Financialization. Work, Employment and Society, v. 25, n. 4, p. 611-626, 2011.

LAZONICK, W. The Financialization of the US Corporation: What Has Been Lost, and How It Can be Regained. The Academic-Industry Research Network. Working Paper, n. 42307, 2012.

LAZONICK, W.; O'SULLIVAN, M. (2000). Maximizing Shareholder Value: A New Ideology for Corporate Governance. Economy and Society, v. 29, n. 1, p. 13-35, 2000.

LOJKINE, J. O estado capitalista e a questão urbana. São Paulo: Martins Fontes, 1981.

MANKIW, G. (2011). Macroeconomia. São Paulo: LTC, 2011.

MARX. K. (1968). O capital. Rio de Janeiro: Civilização brasileira, 1968. Livro 1, Vol. 1.

MARX, K. O capital: crítica da economia política. São Paulo: Nova Cultura, 1985.

MYRDAL, G. Contra a Corrente. Rio de Janeiro: Editora Campus Ltda, 1977.

PAULANI, L. Acumulação Sistêmica, Poupança Externa e Rentismo: Observações Sobre o Caso Brasileiro. Estudos Avançados, v. 27, n. 77, p. 237-261, 2013.

PIKETTY, T. Capital in the Twenty-First Century. Cambridge: The Belknap Press of Harvard University Press, 2014.

RESENDE, M. O Padrão dos Ciclos de Crescimento da Economia Brasileira: 1947-2003. Economia e Sociedade, v. 14, n. 1, p. 25-55, 2005.

SOUZA, M. B. Neoliberalização do Estado no Brasil. Revista e-metropolis. n. 21, ano 6.p. 6-20, 2015.

STOCKHAMMER, E. Financialisation and the slowdown of accumulation. Cambridge Journal of Economics, v. 28, n. 5, pp. 719-741, 2004.

SWEEZY, P. Why Stagnation? Monthly Review, p. 69-77, 2004.

TESOURO. [S.I., 2016]. Disponível em: http://www.tesouro.fazenda.gov.brl. Acesso em 22 nov. 2016.

VAINER,C. Pátria, Empresa e Mercadoria - Notas Sobre A Estratégia Discursiva Do Planejamento Urbano. In: ARANTES, O; VAINER, C.; MARICATO, E. (Orgs.). A cidade do pensamento único. Petrópolis: Vozes, 2002.

VAN DER ZWAN, N. Making sense of financialization. Socio-economic review, v. 19, p. 99-129, 2014 . 


\section{Dados dos autores}

\section{Ana Beatriz Oliveira Reis}

Professora Assistente de Direito do Programa de Ciências Econômicas e Desenvolvimento Regional da Universidade Federal do Oeste do Pará (UFOPA), lotada no Instituto de Ciências da Sociedade (ICS). Mestra em Direito Constitucional pela Universidade Federal Fluminense (PPGDC/UFF). Tem experiência na área de Direito e Planejamento Urbano, com ênfase em Direito Urbanístico atuando principalmente com os temas direito à cidade, legislação urbanística e movimentos sociais. Associada ao Instituto Brasileiro de Direito Urbanístico (IBDU). E-mail: reis.aboliveira@gmail.com

\section{Luccas Assis Attílio}

Professor de Economia da UFOP pelo Departamento de Ciências Econômicas (DEECO). Doutorando em Teoria econômica pela USP (2019), mestre em economia pela UFMG (2014-2016) e graduado em Ciências Econômicas pela UFV (2009-2013). Realiza pesquisas na área de macroeconomia, com ênfase nos tópicos crescimento econômico, sistema financeiro e abertura econômica. Membro do corpo editorial do International Journal of Business and Economics Research (2018). Trabalhou no IBGE (2010), na FAPEMIG (2016) e no Dataviva como colunista (2016-2017). E-mail: luccas.ufop@gmail.com 